\title{
Synthesis, microstructure and thermal properties of photoluminescent hydrogenated amorphous silicon oxide nanopowders
}

\author{
Wei-Fang Su*, Hong-Ru Guo \\ Institute of Materials Science and Engineering, National Taiwan University, Taipei 10627, Taiwan
}

Received 6 December 2000; accepted 7 April 2001

\begin{abstract}
Hydrogenated amorphous silicon oxide photoluminescent nanopowders have been synthesized using a simple solution method involving the reaction of lithium with trichlorosilane in tetrahydrofuran at room temperature. The powders exhibited maximum luminescent peak at $1.1 \mathrm{eV}$ and had an average composition of $\mathrm{SiO}_{0.92} \mathrm{H}_{0.53}$. They possess inhomogeneous microstructures that contain $a-\mathrm{Si}$ clusters $\left(\mathrm{Si}_{3}-\mathrm{Si}-\mathrm{H}\right)$ dispersed in amorphous silica matrix $\left(\mathrm{OSi}_{2}-\mathrm{Si}-\mathrm{H}, \mathrm{O}_{2} \mathrm{Si}-\mathrm{Si}-\mathrm{H}\right)$ in the presence of silanol groups (三Si-OH). DTA, TGA and FTIR analyses showed that the $\mathrm{Si}-\mathrm{H}$ bond was broken at $150{ }^{\circ} \mathrm{C}$ and the hydrogen desorption reached a maximum around $300^{\circ} \mathrm{C}$. The $a$-Si clusters started to crystallize at $650^{\circ} \mathrm{C}$ and formed a single crystal at $1000^{\circ} \mathrm{C}$. () 2002 Elsevier Science B.V. All rights reserved.
\end{abstract}

Keywords: Photoluminescence; Amorphous; Hydrogenated silicon oxide; Nanopowder; Synthesis

\section{Introduction}

The formation of hydrogenated amorphous silicon nanopowders involved in plasma-enhanced chemical vapor deposition (PECVD) process has been reported [1]. This material is expected to be a good precursor for sintering ceramics and for catalytic surfaces. Similar to other silicon photoluminescent materials, such as amorphous silicon [2], porous silicon [3] and silicon nanocrystals [4], silicon nanopowder formed in PECVD shows an intense photoluminescence emission. We have synthesized a disordered, nonregular structure of silicon based photoluminescent materials using a simple wet chemical method by reacting lithium with trichlorosilane in tetrahydrofuran. They were investigated by elemental analysis, Fourier transform infrared spectroscopy (FTIR), Raman spectroscopy, X-ray diffraction (XRD), and transmission electron microscopy (TEM) to determine their microstructures. Their thermal properties were investigated by thermogravimetric analysis (TGA) and differential thermal analysis (DTA).

\section{Experimental}

Hydrogenated amorphous silicon oxide powders were synthesized in a glove box filled with high purity argon

\footnotetext{
* Corresponding author.

E-mail address: suwf@ccms.ntu.edu.tw (W.-F. Su).
}

( $\sim 99.995 \%)$. The argon was dried by passing it through three drying columns: potassium hydroxide, silica gel, and calcium sulfate to maintain the equilibrium water vapor pressure at less than $5 \times 10^{-3}$ Torr according to Ewing method [5]. The tetrahydrofuran (THF, 99.9\%, Fisher Chemical Co.) was dried rigorously by refluxing it for several days over potassium (Tokyo Chemical Industry Co.) and distilled out just before the reaction. All of the glassware was thoroughly dried before reaction. A $0.27 \mathrm{~g}$ (0.04 mole) of lithium ( $99.9 \%$, Aldrich) was reacted with $0.27 \mathrm{~g}$ ( $0.002 \mathrm{~mole})$ of trichlorosilane (Tokyo Chemical Industry Co.) in $30 \mathrm{ml}$ THF under various conditions: no stirring, mechanical stirring, ultrasonic bath, and mechanical stirring plus reflux at $60^{\circ} \mathrm{C}$ for $24 \mathrm{~h}$. A brown solid powder, which was insoluble in organic solvent, was precipitated and removed from the solution. The separated powder was washed several times with dried THF in order to remove lithium chloride by-products. The completeness of washing was determined by titrating the washed THF with a saturated silver nitrate $\left(\mathrm{AgNO}_{3(\mathrm{aq})}\right)(99 \%$, Aldrich) solution until no white silver chloride precipitate was observed. The washed powders were dried under vacuum for more than $24 \mathrm{~h}$, and then were stored in a glove box. From the elemental analysis, the compound has a composition of $\mathrm{SiO}_{0.92} \mathrm{H}_{0.53}$.

Transmission electron microscopy (TEM) (Hitachi H-7100) was used to examine the microstructures and the crystal structures of hydrogenated amorphous silicon powders. The powder sample was suspended in the ethanol and 
dispersed well by ultrasonic vibration. Then a drop of the sample was placed on a carbon grid for TEM examination.

Cross polarization ${ }^{29} \mathrm{Si}$ nuclear magnetic resonance spectrometer $\left({ }^{29} \mathrm{Si} \mathrm{CP}-\mathrm{NMR}\right)$ (Bruker MSL-300 MHz solid state NMR) was used to study structures at a molecular level for synthesized hydrogenated amorphous silicon powders.

The Raman spectroscopy (Renishaw Ramanscope 2000) was used to investigate the structural characteristics of silicon in the hydrogenated amorphous silicon powders with and without heat treatment. The powders were pressed into pellet samples for measurement. A $90^{\circ}$ scattering geometry was used.

FTIR (Nicolet MAGNA-IR 550) was used to study the vibrational frequencies of chemical bonds of the hydrogenated amorphous silicon powders. The powders was mixed with $\mathrm{KBr}$ powders (99.95\%, Aldrich), then pressed to form a disk for measurement.

XRD (Rigaku D/Max II-IV) was used to identify the crystalline phase in the hydrogenated amorphous silicon powders and to measure the structural properties with and without heat treatments. A powder method and monochromatic $\mathrm{X}$-ray beam (radiation wave length $\mathrm{Cu} \mathrm{K} \alpha=0.15418 \mathrm{~nm}$ ) were used.

TGA and DTA (Du Pont, TA 2000 Thermal Analysis System TGA, DTA) were used to study the thermal properties of the powders. The powders were heated in platinum crucibles (the weights of powders were $7.48 \mathrm{mg}$ for TGA and $9.00 \mathrm{mg}$ for DTA). The heating rate was fixed at $5{ }^{\circ} \mathrm{C} / \mathrm{min}$ from $25^{\circ} \mathrm{C}$ to $1000^{\circ} \mathrm{C}$ for both measurements. TGA was done in a vacuum environment $\left(\sim 10^{-3}\right.$ Torr) to avoid residual oxygen in argon. DTA was performed in argon environment.

The photoluminescence experiments were performed in a vacuum chamber with the $488 \mathrm{~nm}$ line of an $\mathrm{Ar}$ ion laser as the excitation source.

\section{Results and discussion}

The powder was synthesized by reacting lithium with trichlorosilane in tetrahydrofuran [6] according to the following reaction:

$$
\mathrm{Li}+\mathrm{HSiCl}_{3} \stackrel{\mathrm{O}_{2} \text { impurity }(\sim 50 \mathrm{ppm})}{\rightarrow} \mathrm{SiO}_{x} \mathrm{H}_{y}+\mathrm{LiCl}
$$

The reaction was carried out in high purity argon $(\sim 99.995 \%)$ at room temperature with stirring. The powders exhibited photoluminescence with a peak at $1.1 \mathrm{eV}$ (Fig. 1) when they were irradiated by a $488 \mathrm{~nm}$ line Ar ion laser. That is similar to the characteristic photoluminescence peak of amorphous silicon. Thus, the photoluminescent origin of our powders can be explained by the CFO (Cohen-Fritzsche-Ovshinsky) model [7] used for photoluminescent amorphous silicon. The luminescence arises from transitions between band-tail states [2].

From the elemental analysis, the average composition of the $\mathrm{SiO}_{x} \mathrm{H}_{y}$ compound was determined to be $\mathrm{SiO}_{0.92} \mathrm{H}_{0.53}$.

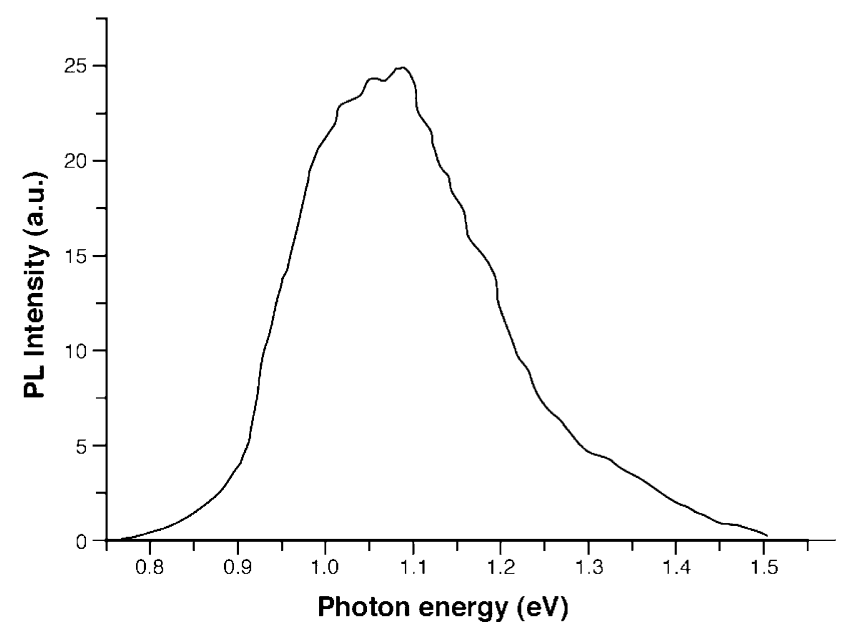

Fig. 1. Typical photoluminescent spectrum of hydrogenated amorphous silicon oxide powders under the excitation of Ar laser $(488 \mathrm{~nm})$. The peak energy is located at $1.1 \mathrm{eV}$.

According to the electronegativity $(\chi), \chi_{\mathrm{Si}}=1.7 ; \chi_{\mathrm{H}}=$ 2.20 [8], the $\mathrm{Si}-\mathrm{H}$ bond is a polar bond with a partial positive charge on silicon atom which can be easily attacked by any electron-rich nucleophiles. Therefore, the oxygen impurity from argon or other sources during the synthesis (e.g. leakage) was incorporated into the $\mathrm{Si}-\mathrm{H}$ bond to form hydrogenated amorphous silicon oxide.

The crystallinity of the powder was determined by TEM and Raman spectroscopy. Fig. 2 shows the TEM micrographs and electron diffraction patterns of the prepared powder at different reaction times. The size of the powder was less than $5 \mathrm{~nm}$ after $6 \mathrm{~h}$ of reaction; however, the particles coagulated into sizes larger than $50 \mathrm{~nm}$ after reacting for $24 \mathrm{~h}$. Electron diffraction patterns show that the powders were amorphous.

The Raman spectrum of the powders shows a broad peak located at $480 \mathrm{~cm}^{-1}$ that is attributed to the $\mathrm{Si}-\mathrm{Si}$ vibration of amorphous silicon [9]. This result implies that the amorphous silicon regions existed in the prepared powder. The local bonding structure of the compound was studied by ${ }^{29} \mathrm{Si}$ CP-NMR (cross polarization nuclear magnetic resonance spectrometer). The up-field peaks between -90 and $-110 \mathrm{ppm}$ reflected the contribution of the oxide bonds in the powder [10,11]. The largest up-field peak at about $-91 \mathrm{ppm}$ was from a $\mathrm{Q}^{2}$ unit $\left((\mathrm{SiO})_{2}-\mathrm{Si}-(\mathrm{OH})_{2}\right.$ or $\left.(\mathrm{SiO})_{2}-\mathrm{Si}_{-} \mathrm{O}_{2}{ }^{-}\right)$. The peak at $-100 \mathrm{ppm}$ was from $\mathrm{Q}^{3}$ groups $\left((\mathrm{SiO})_{3}-\mathrm{Si}(\mathrm{OH})\right.$ or $\left.(\mathrm{SiO})_{3}-\mathrm{Si}_{-} \mathrm{O}^{-}\right)$. The results of elemental and of the ${ }^{29} \mathrm{Si} \mathrm{CP}-\mathrm{NMR}$ analyses suggested that the silanol groups $(\equiv \mathrm{Si}-\mathrm{OH})$ existed in the hydrogenated amorphous silicon oxide powder.

The characteristic vibrational frequencies of $\mathrm{Si}-\mathrm{H}$ bond and $\mathrm{Si}-\mathrm{O}$ bond of our hydrogenated silicon oxide compounds are summarized in the Table 1 . They are in agreement with literature reports $[9,12,13]$. Thus amorphous silicon $(a-\mathrm{Si})$ regions existed in the hydrogenated amorphous silicon oxide matrix. 


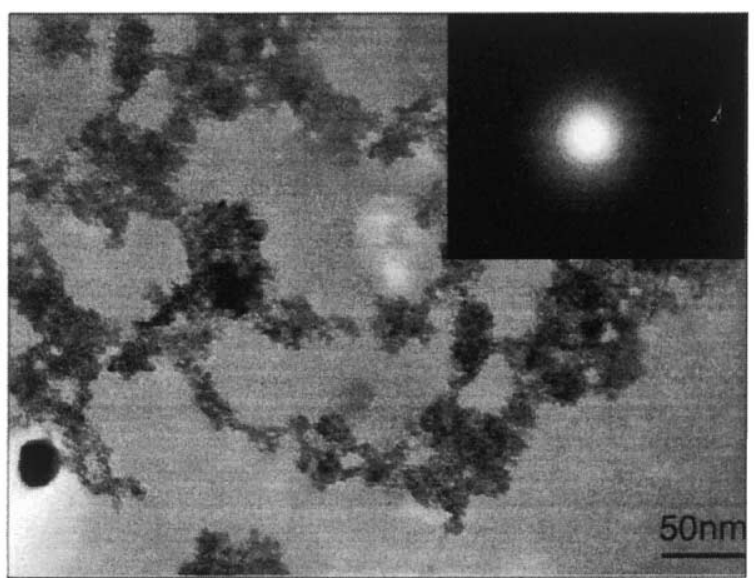

(a)

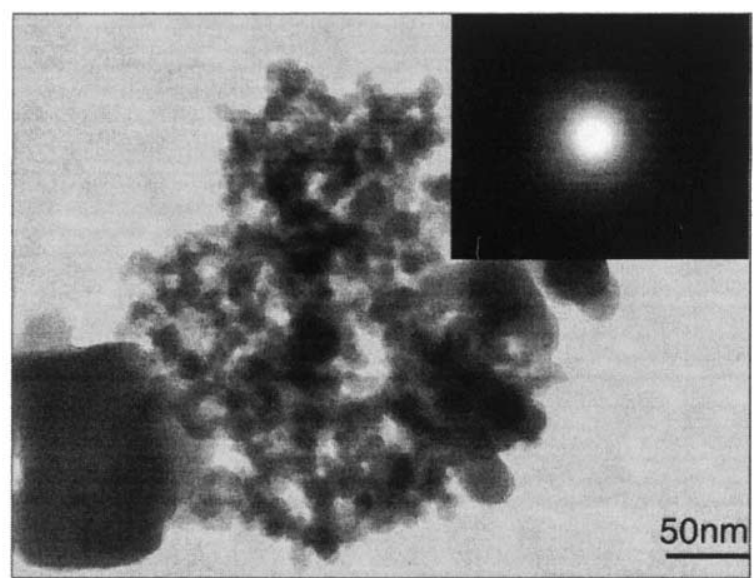

(b)

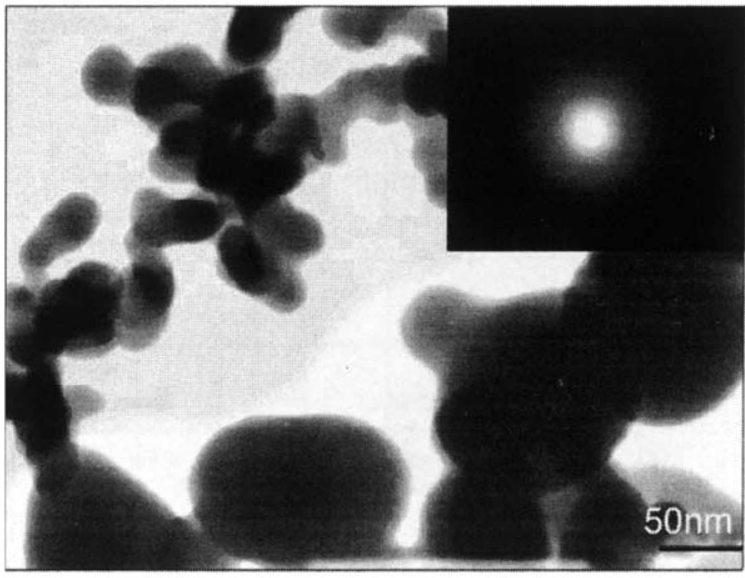

(c)

Fig. 2. TEM micrographs and diffraction patterns of hydrogenated amorphous silicon oxide powders prepared according to various reaction times. (a) $6 \mathrm{~h}$; (b) $12 \mathrm{~h}$; (c) $24 \mathrm{~h}$.

We have studied the effects of reaction conditions on the chemical structures of the powders using FTIR. The results are shown in Fig. 3 and summarized in Table 2. There are four local bonding groups in the sample as $\mathrm{H}-\mathrm{Si}-\mathrm{Si}_{3-z} \mathrm{O}_{z}$ where $z$ is equal to $0,1,2$ and 3 . The only oxygen source in those reactions was from the oxygen impurity of argon environment $(\sim 0.005 \%)$. As seen from Table 2 , the formation of the four chemical bonds was related to the reaction temperature and reaction rate. Fig. 3 shows that the higher the reaction rate, the greater the formation of $\mathrm{H}-\mathrm{Si}-\mathrm{Si}_{3}$ bond-

Table 1

Characteristic vibrational frequencies of $\mathrm{Si}-\mathrm{H}$ bond and $\mathrm{Si}-\mathrm{O}$ bond of hydrogenated silicon oxide

\begin{tabular}{ll}
\hline Type of bond & Frequency $\left(\mathrm{cm}^{-1}\right)$ \\
\hline $\mathrm{Si}_{3}-\mathrm{Si}-\mathrm{H}$ & $2000-2100$ \\
$\mathrm{OSi}_{2}-\mathrm{Si}-\mathrm{H}$ & $2145-2195$ \\
$\mathrm{O}_{2} \mathrm{Si}-\mathrm{Si}-\mathrm{H}$ & 2240 \\
$\mathrm{O}_{3}-\mathrm{Si}-\mathrm{H}$ & 2265 \\
$\mathrm{Si}-\mathrm{O}-\mathrm{Si}$ of $a-\mathrm{SiO}: \mathrm{H}$ & $1010-1040$ \\
$\mathrm{Si}-\mathrm{O}-\mathrm{Si}$ of $\mathrm{SiO}_{2}$ & $1075-1080$ \\
\hline
\end{tabular}

ing in the samples. Although a high reaction temperature usually results in a high reaction rate, we could not find the stretching mode of $\mathrm{H}-\mathrm{Si}-\mathrm{Si}_{3}$ in the powder prepared at $60^{\circ} \mathrm{C}$ reflux condition. This is probably due to the low bonding energy of the $\mathrm{Si}-\mathrm{H}$ (76-kcal/mole) bond, which could not be maintained as easily as the $\mathrm{Si}-\mathrm{O}$ bond with a high bonding energy $(108 \mathrm{kcal} / \mathrm{mole})$. Thus, in our case, the formation of $\mathrm{H}-\mathrm{Si}-\mathrm{Si}_{3}$ was a kinetic controlled process, which could be increased by increasing reaction rate at low temperature. On the other hand, both kinetic and thermodynamic controlled processes were responsible for the formation of $\mathrm{Si}-\mathrm{O}$ bond.

We investigated the thermal properties of the powders using TGA and DTA methods. The TGA data indicated the sample started to lose weight near $150^{\circ} \mathrm{C}$ and reached a constant weight at around $630^{\circ} \mathrm{C}$. The DTA results showed a broad low temperature endothermic peak from 150 to $300{ }^{\circ} \mathrm{C}$, and an exothermic peak at about $650{ }^{\circ} \mathrm{C}$. We observed the disappearance of FTIR vibration peak of $\mathrm{H}-\mathrm{Si}-\mathrm{Si}_{3-z} \mathrm{O}_{z}(z=0,1,2,3)$ for powder annealed at $600^{\circ} \mathrm{C}$. Thus, the DTA endothermic peak indicated that the powder started to loss hydrogen at $150^{\circ} \mathrm{C}$ and finished at 


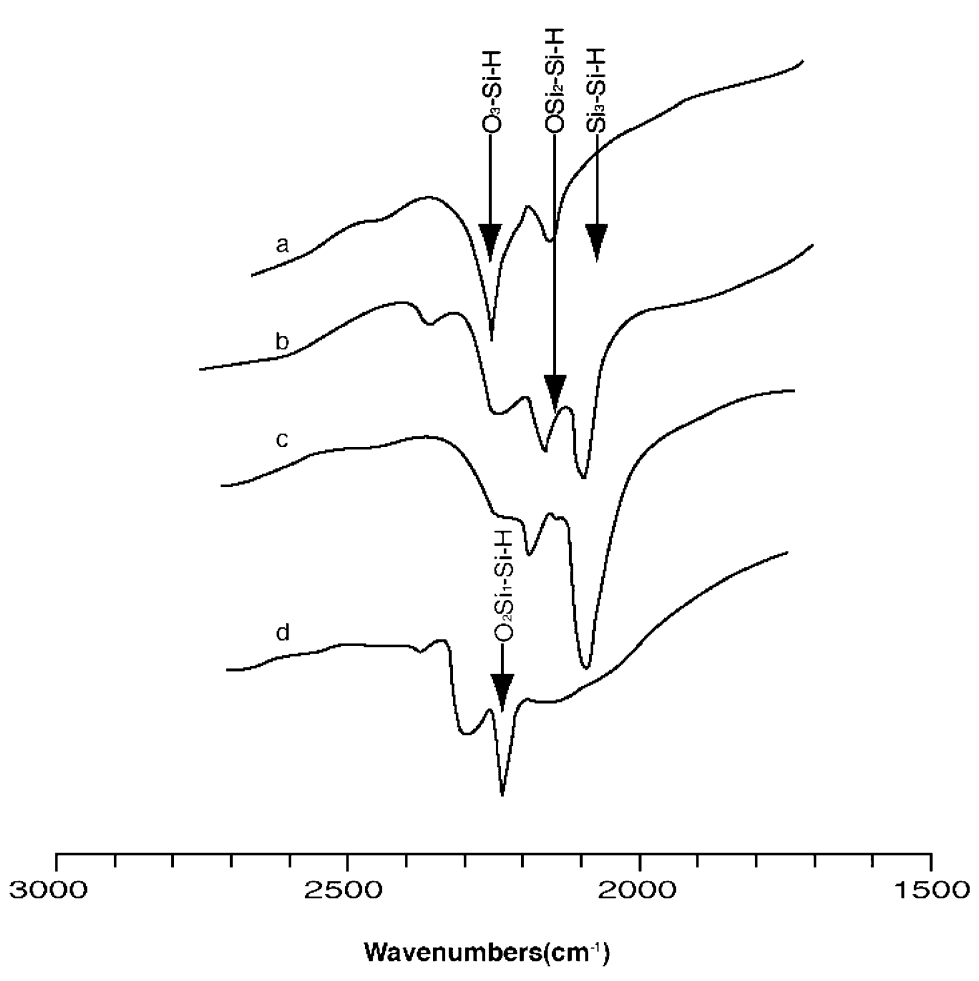

Fig. 3. FTIR spectra of hydrogenated amorphous silicon oxide $\left(1500-3000 \mathrm{~cm}^{-1}\right)$ powders under different reaction conditions. (a) No stirring; (b) Stirring; (c) Ultrasonic; (d) Reflux at $60^{\circ} \mathrm{C}$ plus stirring.

$300^{\circ} \mathrm{C}$. Our results are very similar to that of Costa et al. [1] reported. The hydrogen desorption of hydrogenated amorphous silicon powders started at $200^{\circ} \mathrm{C}$, and reached a maximum around $310^{\circ} \mathrm{C}$. The DTA exothermic peak at about $650{ }^{\circ} \mathrm{C}$ was from the crystallization of amorphous silicon phase of the powder because a silicon crystalline phase was observed in the studies of XRD and TEM for powder annealed at $650^{\circ} \mathrm{C}$.

The studies of XRD showed the powders did not show significant structure changes after they were annealed at $650^{\circ} \mathrm{C}$ for $150 \mathrm{~min}$. However, the TEM micrograph and electron diffraction pattern of that annealed powders showed some silicon crystals embedded in a homogeneous amorphous matrix. Crystallization is not only a thermodynamic process but also a kinetic process. The XRD peak intensities for silicon crystal increase proportionally with increasing anneal- ing time from 150 to $250 \mathrm{~min}$ at $650^{\circ} \mathrm{C}$. Fig. 4 shows the TEM micrographs of the samples annealed at different temperature for $60 \mathrm{~min}$. The nucleus coagulated and grew into a silicon single crystal at $1000^{\circ} \mathrm{C}$. It suggests that a size distribution of $a$-Si clusters existed in the $a$ - $\mathrm{SiO}_{x}$ matrix. Due to thermal fluctuations, these clusters continuously gained and lost silicon atoms. Nucleation even occurred when one of these clusters continued to gain more atoms than it lost. At high temperature $\left(1000^{\circ} \mathrm{C}\right)$, the nucleation of a small nuclei was unfavorable. However, the potential for growth of a large nucleus was favorable. The formation of single crystal in the powders was reasonable. Their nucleation and growth mechanism was similar to the classical phase transformation theory [14].

Banerjee and Loucovsky [15] investigated the thermal stability of $a-\mathrm{SiO}_{x}: \mathrm{H}$. They recognized that $a-\mathrm{SiO}_{x}: \mathrm{H}$ was

Table 2

List of types of $\mathrm{Si}-\mathrm{H}$ bond existing in hydrogenated silicon oxide obtained at different reaction conditions

\begin{tabular}{lllll}
\hline Reaction condition & \multicolumn{2}{l}{ Types of Si-H bond } & & $\mathrm{O}_{2} \mathrm{Si}_{-}-\mathrm{Si}-\mathrm{H}$ \\
\cline { 2 - 4 } & $\mathrm{Si}_{3}-\mathrm{Si}-\mathrm{H}$ & $\mathrm{OSi}_{2}-\mathrm{Si}-\mathrm{H}$ & $\checkmark$ & $\mathrm{O}_{3}-\mathrm{Si}-\mathrm{H}$ \\
\hline No stirring, room temperature & $\times^{\mathrm{a}}$ & $\checkmark$ & $\checkmark$ & $\times$ \\
Mechanical stirring, room temperature & $\checkmark^{\mathrm{b}}$ & $\checkmark$ & $\times$ & $\times$ \\
Ultrasonic stirring, room temperature & $\checkmark$ & $\checkmark$ & $\checkmark$ & $\times$ \\
Reflux at $60^{\circ} \mathrm{C}$, mechanical stirring & $\times$ & $\times$ & $\checkmark$ \\
\hline
\end{tabular}

\footnotetext{
${ }^{\mathrm{a}} \times \mathrm{Si}-\mathrm{H}$ bond was not observed.

b $\checkmark \mathrm{Si}-\mathrm{H}$ bond was observed.
} 


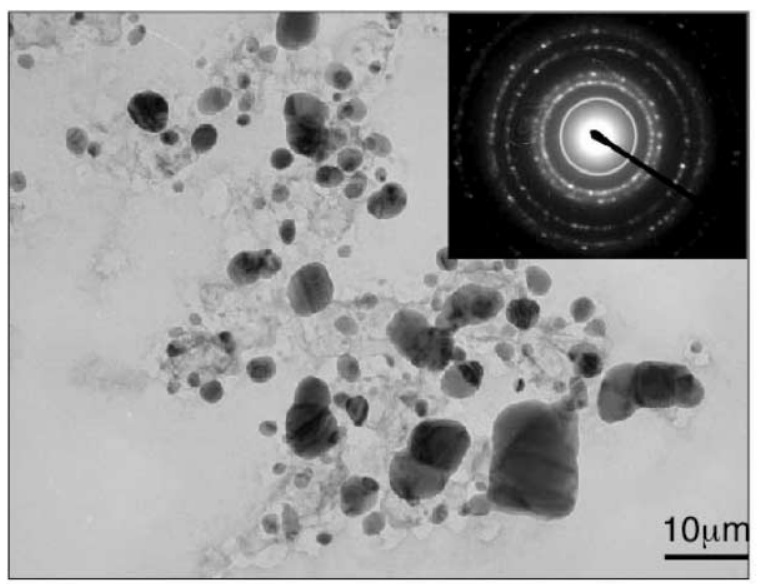

(a)

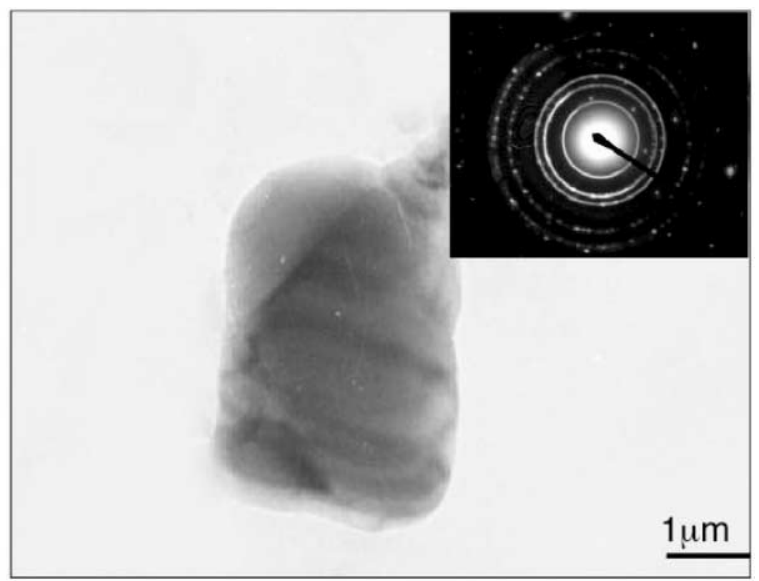

(b)

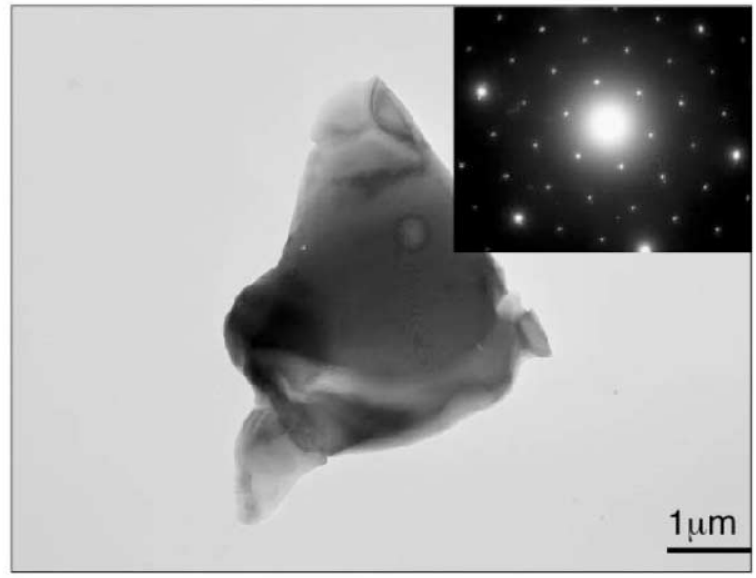

(c)

Fig. 4. TEM micrographs and different diffraction patterns of hydrogenated amorphous silicon oxide powders annealed at (a) $800{ }^{\circ} \mathrm{C}$; (b) $900{ }^{\circ} \mathrm{C}$; (c) $1000^{\circ} \mathrm{C}$.

metastable. A chemical reaction induced phase separation occurred at $900^{\circ} \mathrm{C}$, and crystalline $\mathrm{Si}$ and non-crystalline $\mathrm{SiO}_{2}$ were formed. In our case, from the DTA study, no exothermic or endothermic peaks were observed after $650{ }^{\circ} \mathrm{C}$; consequently, chemical reactions or structural changes did not occur. The structures of the sample were inhomogeneous; $a$-Si clusters and $a-\mathrm{SiO}_{x}$ coexisted. The $a$-Si clusters can be considered as potential nuclei; therefore, the crystallization occurred at a lower temperature than that of Banerjee and Lucovsky.

\section{Conclusions}

Hydrogenated amorphous silicon oxide photoluminescent nanopowders have been synthesized using a simple solution method involving the reaction of lithium with trichlorosilane in tetrahydrofuran at room temperature. The luminescent peak energy is located at $1.1 \mathrm{eV}$. Elemental analysis showed the powder to have average chemical composition of
$\mathrm{SiO}_{0.92} \mathrm{H}_{0.53}$. Raman, ${ }^{29} \mathrm{Si}$ CP-NMR and FTIR spectra analyses indicated that the powder has silanol groups ( $\equiv \mathrm{Si}-\mathrm{OH})$ and $a$-Si clusters $\left(\mathrm{Si}_{3}-\mathrm{Si}-\mathrm{H}\right)$ coexisting in the amorphous silica matrix $\left(\mathrm{OSi}_{2}-\mathrm{Si}-\mathrm{H}, \mathrm{O}_{2} \mathrm{Si}-\mathrm{Si}-\mathrm{H}\right)$. The formation of $\mathrm{H}-\mathrm{Si}$ bonding is a kinetic controlled process, whereas the formation of $\mathrm{O}-\mathrm{Si}$ is both a kinetic and thermodynamic controlled process. The DTA, TGA and FTIR analyses show the $\mathrm{Si}-\mathrm{H}$ bond of powder was broken at $150^{\circ} \mathrm{C}$ and hydrogen desorption reached a maximum around $300^{\circ} \mathrm{C}$. The $a$-Si clusters of powder started to crystallize at $650^{\circ} \mathrm{C}$ and formed a single crystal at $1000^{\circ} \mathrm{C}$.

\section{Acknowledgements}

The financial supports obtained from the National Science Council of Republic of China (NSC-88-2216-E-002-006) and the Industrial Technology Research Institute, Electronics Research and Service Organization (1997-1998) were highly appreciated. 


\section{References}

[1] J. Costa, P. Roura, G. Sardin, J.R. Morante, E. Bertan, Appl. Phys. Lett. 64 (1994) 463.

[2] R.A. Street, Adv. Phys. 30 (1981) 593.

[3] L.T. Canham, Appl. Phys. Lett. 57 (1990) 1046.

[4] S. Furukawa, T. Hiyasato, Phys. Rev. B 36 (1988) 5726.

[5] G.W. Ewing, J. Chem. Ed. A47 (1970) 815.

[6] P. John, I.M. Odeh, M.J.K. Thomas, J.I.B. Wilson, J. Dev. Physiol. C42 (1981) 4-651.

[7] M.H. Cohen, H. Fritzsche, S.R. Ovshinsky, Phys. Rev. Lett. 22 (1969) 1065.

[8] J.B. Umland, General Chemistry, West Publishing Company, St. Paul, M.N., 318, 1993.
[9] R.A. Street, in: J. Pankkove (Ed.), Semiconductors and Semimetals, Academic Press, New York, 1984.

[10] A. Tuel, H. Homml, A.P. Legrand, E. Kovats, Langmuir 6 (1990) 770.

[11] E. Lippmaa, M. Magi, A. Samoson, G. Engelhardt, A.-R. Grimmer, J. Am. Chem. Soc. 102 (1980) 4889-4893.

[12] D.V. Tsu, G. Lucosky, B.N. Davidson, Phys. Rev. B40 (1989) 1795.

[13] G. Lucovsky, J. Non-Cryst. Solids 1 (1998) 227-230.

[14] D.A. Porter, K.E. Easterling, Phase Transformations in Metal and Alloy, Chapman \& Hall, New York, 1992.

[15] A. Banerjee, G. Lucovsky, MRS Symp. Proc. 420 (1995) 505. 